\section{PCPD Editorial}

The arguments for and against the early detection of prostate cancer, as well as the optimum form of treatment for those diagnosed with clinically confined prostate malignancy have continued to exercise the minds of urologists and oncologists in several recent international meetings. At the American Urological Association meeting in San Diego in June 1998 the screening issue constituted the subject of the "Great Debate". The views expressed and data quoted on both sides are summarised by Arie Belldegrun in the "What's Hot" section of this issue of Prostate Cancer and Prostatic Diseases.

In the UK the Department of Health has recently issued a press release concluding that "a national screening programme for prostate cancer, with current techniques, is of no benefit to the male population and could cause considerable harm". Several new pieces of information however have brought the concession from Dr Muir-Gray, advisor to the UK government on screening, to look again at the evidence. First Jacobsen $e t a l^{1}$ in a case control study concluded that digital rectal examination (DRE) might protect against $50 \%$ of deaths from metastatic cancer. Second, Labrie et al, in the first reported randomised controlled trial (RCT) of prostate cancer screening, reported a $67 \%$ reduction in mortality in the screened cohort. $^{2}$ Thirdly, in the USA where up to $70 \%$ of men between 40 and 65 know what their own prostate specific antigen (PSA) value is, both the incidence and mortality of prostate cancer are, for the first time, beginning to decline. $^{3}$

The case for early detection is undoubtedly weakened by the uncertainty surrounding the optimal form of management for clinically localized disease. Savage et $a l^{4}$ documented the variation in treatment preferences among UK urologists; however poorly structured postal questionnaires such as this are notoriously unreliable. In the USA and elsewhere, urologists look to the metastatic rate of around $50 \%$ of men managed by watchful waiting and compare that with the normal life expectancy of those undergoing radical prostatectomy for organ confined disease, and counsel their patients accordingly.
As pointed out recently by Mulley and Barry, ${ }^{5}$ the conclusions of the Prostate Cancer Guidelines Panel of the American Urological Association are that clinicians should at this stage avoid firm recommendations for patients with clinically localised prostate cancer. Instead treatment alternatives should be presented as options, each with its advantages and disadvantages. Educational programmes on treatment options that reflect the preferences and attitudes of the individual patient have been shown to be feasible in busy urology practices.

RCTs of both screening and treatment options for prostate cancer are ongoing and should eventually provide us with the certainty that we all would like. In the meantime it is our duty to carefully and compassionately provide the patient and his family with the balanced information they need. It is critical that they feel happy in themselves with the decision they eventually come to, either about PSA testing itself, or the treatment of any lesion discovered as a result of the measurement of that serum marker. The challenge for all of us is to improve our communication skills so as to make this possible.

RS Kirby

\section{References}

1 Jacobsen SJ et al. Population-based study of digital rectal examination and prostate cancer mortality. J Urol 1998; 159: 126A.

2 Charatan FB. Prostate cancer screening reduces deaths. BMJ 1998; 316: 1626.

3 Krongrad A, Lai H, Lamm SH, Lai S. Mortality in prostate cancer. J Urol 1996; 156: 1084-1091.

4 Savage P, Bates C, Abel P, Waxman J. British urological surgery practice. Br J Urol 1997; 79: 749-755.

5 Mulley AG, Barry MJ. Controversy in managing patients with prostate cancer. BMJ 1998; 316: 1919-1920.

6 Middleton RG et al. Prostate cancer clinical guidelines panel summary report on the management of clinically localized prostate cancer. J Urol 1995; 154: 2144-2148. 